\title{
Práticas pedagógicas do Pibid Ciências da Natureza: mapeando tendências
}

\author{
Pedagogical practices of Pibid Science of Nature: mapping trends
}

\author{
Eril Medeiros da Fonseca ${ }^{1}$ \\ Crisna Daniela Krause Bierhalz ${ }^{2}$
}

\section{Resumo}

Este trabalho busca identificar tendências temáticas, teóricas e metodológicas nas práticas pedagógicas realizadas pelo Programa Institucional de Bolsas de Iniciação à Docência (Pibid), no subprojeto Ciências da Natureza, vinculado à Unipampa - Campus Dom Pedrito. Para isso analisaram-se os relatórios de produção do Programa (2018-2019) a partir de três eixos definidos a priori: abordagem de temas, tendências teóricas e metodológicas. As informações foram organizadas por meio da análise de conteúdo seguindo as etapas de leitura, aproximação com os eixos temáticos e sistematização das informações. Verificou-se que a abordagem de temáticas ambientais, como as relacionadas ao bioma Pampa e aspectos presentes na realidade do estudante prevaleceu nas práticas analisadas. Pôde-se notar que não há uma metodologia definida, mas as práticas são balizadas, em geral, por uma concepção progressista de ensino. Além disso, o Programa parece ancorar-se em referenciais próximos a ideia de contextualização. Destaca-se, ainda, a abordagem dialogada nas práticas de ensino, os planejamentos coletivos e a contribuição para constituição da identidade do professor.

Palavras-chave: Ensino de Ciências. Contextualização. Relatórios de produção.

\begin{abstract}
This work seeks to identify thematic, theoretical and methodological trends in the pedagogical practices carried out by PIBID, in the Nature Sciences subproject, linked to Unipampa - Dom Pedrito Campus. Thus, the production reports of the Program (20182019) were analyzed at first from three specific axes: thematic, theoretical and methodological trends. The information was organized through the content analysis following the reading steps; approximation with the thematic axes and systematization of information. It was noticed the approach of environmental themes such as the Pampa Biome and the aspects present in the student's reality; there is no defined methodology, but the practices are generally based according to a progressive conception of teaching. Furthermore, the Program seems to be supported by references close to the idea of contextualization. We can still highlight the dialogue approach in teaching practices, collective planning and the contribution to the constitution of the teacher's identity.
\end{abstract}

\footnotetext{
${ }^{1}$ Licenciado em Ciências da Natureza, mestre em Ensino, doutorando em Educação Científica e Tecnológica, professor na rede municipal de Dom Pedrito/RS. Email: erilmf@gmail.com

2 Pedagoga, mestre e doutora em educação, é professora associada na Universidade Federal do Pampa. Email: crisnabierhalz@unipampa.edu.br
} 


\section{-Revista de Iniciação à Docência, v.6, n.2, 2021- \\ Publicação: dezembro, 2021 - ISSN 2525-4332}

Keywords: Teaching Science. Contextualization. Report Production.

\section{Primeiras palavras e aspectos metodológicos}

O Programa Institucional de Bolsas de Iniciação em nível superior para a educação básica; contribuir para a valorização à Docência (Pibid) constitui-se, desde 2013, como uma política pública educacional, inserida na Lei de Diretrizes e Bases da Educação Nacional (BRASIL, 1996), contemplando três dimensões que se complementam e se articulam: docentes em processo de formação; docentes da educação básica e formadores de professores. Dentre seus objetivos, destacam-se: incentivar e qualificar a formação de professores do magistério; promover a interação entre universidade e escola e proporcionar oportunidades de criação e participação em experiências metodológicas (CAPES, 2014).

Dentre os programas nacionais vigentes relacionados à formação de professores, acredita-se que o Pibid consegue realizar, já na primeira metade dos cursos de licenciatura, uma articulação entre o contexto vivenciado na educação superior e o ambiente escolar, além de contribuir para uma aproximação prática com o cotidiano das escolas públicas.

Alguns trabalhos no campo do ensino de Ciências têm apontado contribuições significativas do Programa para na formação de professores, a exemplo das potencialidades e limitações individuais e grupais que licenciandos apontam (SILVEIRA; OLIVEIRA; NOGUEIRA, 2019); possibilidade de medição das relações entre os participantes dos subprojetos e inserção dos supervisores como co-formadores (NOGUEIRA; FERNANDES, 2019) e, ainda, contribuição das vivências na escola para a formação dos bolsistas do Programa (SANTOS; SANTOS; FERREIRA, 2019).

Em trabalho anterior (FONSECA; BIERHALZ, 2018) buscando identificar contribuições e limitações do PIBID na formação de professores, foi realizado um levantamento, nas atas do Encontro Nacional de Pesquisa em Educação Ciências (ENPEC), de 2007 a 2015, percebeu-se a integração entre as universidades e a educação básica por meio da inserção dos licenciandos em espaços de ensino e a consolidação da formação docente, tanto inicial, como continuada.

Além disso, esse trabalho sinalizou a necessária superação da resistência dos professores em assumirem a formação compartilhada dos bolsistas, bem como em dedicar maior tempo para questões de cunho teórico. Por isso, é necessário o delineamento sobre as dimensões teóricas e também metodológicas que pautam as práticas desse Programa.

Nesse sentido, surgem algumas questões, tais como: Como o Ensino de Ciências se insere nas práticas realizadas pelo PIBID? Que temáticas, discussões, encaminhamentos teóricos e práticas metodológicas têm sido articuladas? É possível identificar 


\section{-Revista de Iniciação à Docência, v.6, n.2, 2021- \\ Publicação: dezembro, 2021 - ISSN 2525-4332}

metodologias e conceitos predominantes ou a pluralidade de ideias é convergente com os processos educativos realizados na área?

Diante desse contexto e em consonância com esses questionamentos, busca-se neste trabalho identificar tendências temáticas (temas mais recorrentes nas práticas realizadas pelo PIBID - Ciências da Natureza), teóricas e metodológicas nas práticas pedagógicas realizadas pelo PIBID, especificamente no subprojeto Ciências da Natureza, vinculado à Unipampa - campus Dom Pedrito.

Para atender a esta demanda, analisou-se os relatórios de produção do Programa referentes a 2018 e 2019. Esse período justifica-se por algumas reformulações que o PIBID passou a partir da inserção do Programa Residência Pedagógica, implantado em 2018. Com isso o PIBID passou a trabalhar apenas com os licenciandos do primeiro ao quinto semestres. Além disso, a dinâmica de trabalho também foi modificada, incorporando o estudo e planejamento das estratégias e intervenções, seguido do reconhecimento da realidade, para reorganização e aplicação das propostas.

Os relatórios são subdivididos em tipos de atividades, entre elas: produção de materiais; planejamentos; intervenções; grupos de estudo; gincanas; olimpíadas e eventos e atividades experimentais. Para as análises foram considerados três eixos específicos a priori: abordagem de temas, tendências teóricas e metodológicas.

A partir de aproximações, com a análise de conteúdo de Bardin (2009), realizou-se um procedimento analítico em etapas. Em um primeiro momento fez-se uma leitura flutuante dos materiais, identificando a forma de organização e distribuição das atividades. Posteriormente buscou-se perceber aproximações das práticas realizadas nos eixos estipulados e, por fim, sistematizaram-se as principais informações em cada eixo.

Tendo como referência tais eixos serão apresentados a seguir as características e particularidades que compõem cada um.

\section{Eixo 1 - Abordagem de temas}

O mapeamento das tendências temáticas nos relatórios do Programa indicou a prevalência de dois grandes temas, que parecem ser trabalhos por todos os grupos de trabalho do PIBID no subprojeto Ciências da Natureza, a saber: Bioma: bioma Pampa e energia.

A abordagem sobre o bioma Pampa é ampla, com relações diretas e específicas, considerando-se o contexto local e uma ampla diversidade de aportes metodológicos e recursos didáticos, em formato de sequência didática. Já o tema energia foi abordado apenas em intervenções pontuais, com diferentes enfoques e direcionamentos para o entendimento de conteúdos conceituais.

No Ensino de Ciências, o bioma Pampa tem sido abordado amplamente, em 


\section{-Revista de Iniciação à Docência, v.6, n.2, 2021- \\ Publicação: dezembro, 2021 - ISSN 2525-4332}

especial com foco para a Educação Básica. Castro, Carvalho e Pessano (2019) investigaram as percepções de estudantes da Educação Básica sobre os conhecimentos relacionados ao Pampa e constataram que a maioria dos alunos possui percepções inadequadas e fragmentadas sobre esse bioma, com isso sugerem a promoção de atividades contextualizadas para expansão do conhecimento ambiental da região. Castro (2018), investigando a abordagem do referido bioma em livros didáticos de Ciências e Biologia, percebeu que dentre os biomas brasileiros o Pampa é o menos abordado, apresentando informações resumidas, muitas vezes indicando que esse bioma é útil para a agropecuária, sem apresentar informações biológicas. Não havendo, portanto, uma contextualização significativa, pois poderiam ser realizadas intervenções com os estudantes e professores no sentido de proporcionar uma relação de conhecimento maior com o tema estudado. Defende-se que uma aproximação dos estudantes com aspectos e problemáticas locais propiciam um engajamento e interação com o ambiente em que vivenciam em um maior grau. Caminha (2019) também investigou a compreensão de estudantes do ensino fundamental sobre o bioma Pampa e percebeu que os discentes desconheciam a flora e outras características do bioma como um todo.

A abordagem de temáticas ambientais ou de questões relacionadas aos ecossistemas é indicada em documentos oficiais. Os Parâmetros Curriculares Nacionais para Ciências da Natureza (BRASIL, 1998) sugerem a inserção de temáticas ambientais ainda no início do ensino fundamental, para que os estudantes compreendam o ambiente em que vivem. Além disso, ressaltam a importância de uma visão universal dos estudantes, mas indicam que os estudantes compreendam o ambiente em que vivem para o exercício da cidadania, a fim de que esse estudo não se torne um trabalho exclusivamente livresco3 ${ }^{3}$. De forma análoga, a Base Nacional Comum Curricular - BNCC (BRASIL, 2017) propõe o estudo de aspectos ambientais, como a preservação da biodiversidade e a distribuição geográfica dos principais ecossistemas brasileiros.

A realização de processos educativos a respeito desse tema tem se mostrado importante para a região da campanha, no interior do Rio Grande do Sul. Desse modo, percebe-se que as práticas realizadas pelo subprojeto Ciências da Natureza parecem ser coerentes com uma abordagem contextualizada, que abrange questões contextualizadas, ou seja, abordam aspectos presentes no contexto local. Esses aspectos estão alinhados bem como alinhadas à discussão de demandas ambientais, já que o bioma Pampa está presente em cerca da metade sul e a região sudoeste do Rio Grande do Sul apresentando, segundo Bencke (2006), desde serras até planícies, morros e coxilhas, constituindo um patrimônio cultural associado à biodiversidade.

É importante ressaltar que as demandas e formas de execução do subprojeto

\footnotetext{
3 Entendemos como trabalho livresco uma prática de ensino que é focada exclusivamente na abordagem de conteúdos conceituais, guiando-se, especialmente, por livros didáticos. Com isso, não significa que esses recursos não devem ser utilizados, mas basear-se apenas neles para desenvolver as atividades didáticas seria um reducionismo da prática pedagógica.
} 


\section{-Revista de Iniciação à Docência, v.6, n.2, 2021- \\ Publicação: dezembro, 2021 - ISSN 2525-4332}

Ciências da Natureza parecem ser comuns a todos os grupos de trabalho do PIBID, já que todos desenvolveram os planejamentos por meio de sequências didáticas. Além disso, utilizaram recursos didáticos específicos como as Tecnologias de Informação e Comunicação (TIC), elaboração de mapas e esquemas mentais e relações entre componentes curriculares.

A abordagem sobre o bioma Pampa também é coerente com intervenções realizadas em Educação Ambiental já que por abranger um contexto amplo a ser explorado, é possível assumi-lo para além de um tema, mas sim como um eixo estruturante de currículos, com diferentes enfoques e aprofundamentos, destinado a um ano letivo, semestre ou demandas específicas, como as realizadas pelos grupos de trabalho, por meio das sequências didáticas. A partir desse eixo estruturante podem ser articuladas algumas temáticas ou subtemas, como a produção de leite, o uso de ervas medicinais (arnica, pitanga e babosa) e os animais que ocorrem no referido bioma.

Alguns trabalhos feitos pelos grupos de trabalho do PIBID subprojeto Ciências da Natureza realizaram articulações com questões culturais locais a exemplo do uso das ervas medicinais pela população. Essa abordagem aproxima-se do trabalho com saberes populares, indicado por Chassot (2008). Esse autor afirma que esses são conhecimentos que fazem parte da prática cultural de determinado grupo, sendo importante investigar e resgatar essas práticas enquanto saberes escolares. Também menciona que os conhecimentos estudados precisam estar "encharcados da realidade" (CHASSOT, 2004), contextualizando-os com aspectos históricos, sociais, políticos e econômicos.

Para Silva e Milaré (2018) a discussão dos saberes populares em aula é uma potencialidade, já que podem ser abordados a partir de leis e teorias científicas, considerando que ambos os saberes coexistem enquanto produção humana e visões de mundo. As autoras mencionam que discussões sobre desmitificação da Ciência também podem ser tecidas, promovendo a tomada de decisão, em que os estudantes podem refletir sobre crenças e o impacto das informações, bem como buscar ideias. Nessa perspectiva, argumenta-se que pode ser desenvolvida uma visão crítica em relação a aspectos presentes na realidade, proporcionando o desenvolvimento de uma postura consciente em relação a questões ambientais a exemplo da preservação e cuidado com a fauna e flora do bioma Pampa.

Abordagens que envolvam dimensões dos saberes populares, ou crenças de forma geral, possibilitam trabalhar conceitos de várias áreas e fazer relações com questões econômicas. Silva e Milaré (2018) citam a avalição de relações custo-benefício ou economia doméstica, que se mostra presente em alguns planejamentos do Programa, por exemplo nos que abordam o uso de ervas medicinais. Tal abordagem em sala de aula perpassa também as condições de trabalho e formação dos professores, além da utilização de metodologias e recursos didáticos.

A estrutura dos planejamentos está próxima do que se denomina de abordagem 
temática, ainda que as práticas (pelo que se observa nos relatórios) não estejam totalmente alinhadas com as bases teóricas que sustentam uma abordagem temática. Para Delizoicov, Angotti e Pernambuco (2011) essa se configura como uma proposta em que a escolha dos conteúdos é subordinada ao tema, ou seja, os conceitos científicos do programa escolar são trabalhados a partir de uma determinada temática. Assim, algumas possibilidades de trabalho com temas podem ser aprofundadas. Essas vêm destacando-se em pesquisas em Ensino de Ciências a exemplo da Educação Ciência-TecnologiaSociedade (CTS) (CENTA; MUENCHEN, 2018; MILLI; ALMEIDA; GEHLEN, 2018) e articulações de CTS com os princípios freireanos (FONSECA, 2019).

Pode-se dizer que as práticas educativas realizadas pelo subprojeto Ciências da Natureza, se aprofundadas nessa concepção de abordagem temática, podem constituir processos mais amplos de reestruturação curricular, somente se trabalhados a partir de uma problemática, em que se busca compreender uma questão central do contexto durante o processo educativo. No entanto, assumindo-se esse tipo de abordagem, as produções do Programa demonstram certa fragilidade.

Percebe-se, também, que os planejamentos são coerentes com as orientações e objetivos para Ciências da Natureza indicados pela BNCC (BRASIL, 2017), já que a elaboração das sequências didáticas e planos de aula trazem objetivos específicos indicados pelo documento. Flôr e Trópia (2018), analisando o discurso presente nesse documento, colocam alguns aspectos a serem repensados. Há um sentido de discurso autoritário, o que reforça a possibilidade de leitura apenas por uma única forma de compreender um texto, dando ênfase para a aprendizagem, subentendendo a dimensão do ensino como algo resolvido pelo próprio documento. Os autores mencionam que o texto da BNCC, nas condições de sua produção, indica uma leitura literal, em que o leitor se torna cumpridor das orientações. Nas palavras desses: “[...] a leitura do documento leva à antecipação de um leitor obediente, cumpridor da lei e de seus deveres, na medida em que faz valer os direitos e objetivos de aprendizagem veiculados na BNCC" (FLÔR; TRÓPIA, 2018, p. 154).

Com isso, é possível dizer que os planejamentos realizados pelo Programa estão em sintonia com referenciais teóricos e metodológicos da BNCC, porém apenas com a leitura do relatório não é possível afirmar que as práticas desenvolvidas estão pautadas exclusivamente pelas orientações da BNCC. Flôr e Trópia (2018) também fazem menção ao extrato de Ciências da Natureza presente no documento. Há uma naturalização de conceitos em disputa na área, como o letramento científico, que acaba intencionando uma única forma de leitura, ao mesmo tempo em que silencia outras. Essas questões não constituem o foco das análises, portanto não são feitos maiores aprofundamentos, ainda que seja pertinente indicar algumas reflexões como: Em que medida são feitas análises/leituras críticas do documento anteriores à efetivação de práticas educativas? A utilização da BNCC como aporte teórico-metodológico permite uma abordagem plural ou unidirecional dos objetivos de ensino? 
-Revista de Iniciação à Docência, v.6, n.2, 2021-

Publicação: dezembro, 2021 - ISSN 2525-4332

Segundo os planejamentos revisados, as práticas pedagógicas indicam esforços de ações interdisciplinares, já que abordam conceitos de várias áreas do conhecimento (Ciências Humanas, Linguagens e Matemática) em uma mesma intervenção, em torno de uma mesma temática. Auler (2007) aponta que o trabalho com temas encaminha a perspectiva interdisciplinar, considerando a complexidade que as temáticas remetem. Nesse movimento, os conceitos de cada área do conhecimento deixam de ser estudados isoladamente para se articularem em torno de objetivos comuns. As práticas do PIBID realizam essa articulação, inclusive trabalhando conceitos de outras áreas. Isso pode ser considerado uma potencialidade que o Programa proporciona. É importante mencionar que tais planejamentos são realizados no coletivo, já que consta sempre mais de um autor.

O que se mostra pelas produções do Programa, para além de um trabalho coletivo ou articulações com a perspectiva temática, é a relevância de considerar, em diferentes medidas, aspectos do contexto em que estão sendo realizadas as práticas. É importante sinalizar que os processos educativos realizados pelo Programa são coerentes com a perspectiva da contextualização, indicada por documentos legais, como a BNCC, porém também é pertinente um aprofundamento em questões que abarcam o contexto em práticas educativas.

Trabalhar questões do contexto não é o mesmo que trabalhar o interesse dos estudantes, que também é diferente de processos que abordam a realidade vivenciada por eles. O que se percebe na abordagem do tema bioma Pampa é que esse abarca o contexto da região da campanha do Rio Grande do Sul e, portanto, possibilita trabalhar aspectos presentes no contexto dos estudantes, já que se trata do bioma presente no município de Dom Pedrito, onde o Programa aqui analisado foi desenvolvido. Essa abordagem não necessariamente abrange o cotidiano dos discentes, mas é coerente com uma possibilidade contextualizada de ensino. Sobre essa questão Chassot (2004) aponta que a listagem de conteúdos pode ser pensada a partir da realidade do estudante, elencando temas que são de interesse desses ou da sua comunidade. Trabalhos nessa perspectiva têm sido desenvolvidos no Ensino de Ciências como o de Centa e Muenchen (2018).

Em síntese, pode-se considerar que o Programa aborda a perspectiva temática, dando ênfase ao trabalho com questões presentes na realidade, a exemplo do bioma Pampa com desdobramentos para o uso das ervas medicinais. Ainda que não tenham sido explicitados critérios de escolha da temática, o trabalho pedagógico caracteriza uma perspectiva contextualizada de ensino, além de assumir um caráter coletivo de planejamento das propostas.

\section{Eixo 2 - Tendências metodológicas}

A partir das propostas e planejamentos revisados nos relatórios pode-se dizer que 


\section{-Revista de Iniciação à Docência, v.6, n.2, 2021- \\ Publicação: dezembro, 2021 - ISSN 2525-4332}

não há um aporte metodológico definido nos projetos analisados. Pode-se apenas indicar que as abordagens didáticas utilizadas são coerentes com uma concepção progressista de ensino, que considera os estudantes como seres pensantes, a exemplo das práticas dialogadas presentes nos planejamentos. A falta de clareza de uma definição metodológica pode ser justificada pelo fato da reestruturação na dinâmica do Programa, pois esse contém, atualmente, apenas licenciandos dos primeiros anos dos cursos de Licenciatura, períodos em que a experiência com intervenções de ensino ainda não é ampla.

Como ressaltado anteriormente, algumas estratégias parecem ser comuns a todos os grupos de trabalho, entre elas ressalta-se o uso da sequência didática, uma estratégia que predomina nos planejamentos, bem como intervenções pontuais feitas a partir do uso de planos de aula.

Foi possível identificar algumas estratégias alternativas, tanto nas sequências didáticas, quanto nos planejamentos mais pontuais, entre elas a utilização de Tecnologias de Informação e Comunicação (TICs), atividades práticas, jogos didáticos, entre outros.

Os focos a partir do bioma Pampa foram: quero-quero, pitanga, nicho ecológico, efeito estufa, babosa, produção de leite, animais em extinção, plantas medicinais, biomas brasileiros de forma geral e aspectos bióticos e abióticos do bioma, como fauna, flora, clima e relevo. Em relação ao tema energia, as intervenções focaram em: tipos e fontes de energia (solar, eólica, estática, termelétrica, luminosa) e leis da conservação de energia.

As estratégias didáticas e recursos utilizados nos vinte e três planejamentos analisados - sequências didáticas e planos de aula - estão sistematizados no quadro a seguir (Quadro 1):

Quadro 1: Incidência das estratégias didáticas e recursos utilizados nos planejamentos analisados.

\begin{tabular}{|l|l|l|}
\hline $\begin{array}{l}\text { Estratégia didática/recursos } \\
\text { utilizados }\end{array}$ & $\begin{array}{l}\text { Número de vezes que } \\
\text { apareceram }\end{array}$ & $\begin{array}{l}\text { Percentual equivalente } \\
(\%)\end{array}$ \\
\hline Leitura de texto & 4 & 17,39 \\
\hline Atividades práticas & 16 & 69,56 \\
\hline Modelo didático & 1 & 4,34 \\
\hline $\begin{array}{l}\text { Utilização de Tecnologias da } \\
\text { Informação e Comunicação }\end{array}$ & 3 & 13,04 \\
\hline Utilização de imagens & 2 & 8,69 \\
\hline Jogo/modelo didático & 5 & 21,73 \\
\hline
\end{tabular}


Quadro 1: Incidência das estratégias didáticas e recursos utilizados nos planejamentos analisados. (continuação)

\begin{tabular}{|l|l|l|}
\hline Projeção & 2 & 8,69 \\
\hline Vídeo & 2 & 8,69 \\
\hline Questionário presencial e online & 4 & 17,39 \\
\hline Dinâmica de grupo & 4 & 17,39 \\
\hline
\end{tabular}

Fonte: Autores (2021)

A partir do Quadro 1 pode-se observar a utilização de atividades práticas $(69,56 \%)$, seguida de jogo/modelo didático (21,73\%), leitura de textos, questionários e dinâmica de grupo (17,39\%). O uso das TICs também parece ser recorrente $(13,04 \%)$.

Consideram-se como atividade prática todos os momentos em que foram realizados experimentos e práticas experimentais de forma geral. A utilização das TICs se deu por meio de aplicativos e aparelhos eletrônicos. É possível observar que os processos realizados pelo Programa, quase que de forma predominante, utilizam atividades práticas e/ou jogos/modelos didáticos, o que atribui um caráter dinâmico, diferente das atividades que comumente são realizadas na Educação Básica. Esse aspecto contribui para renovar as práticas dos docentes das escolas, bem como proporcionar momentos e oportunidades diferenciadas de aprendizagem.

Além dessas estratégias e recursos didáticos, foram identificados, com menos frequência, a utilização de histórias em quadrinho, observação de fenômenos e aulas expositivas. A produção de vídeos também se destacou, havendo o registro de 11 produções sobre as leis de Newton.

Ainda que não seja possível delinear um caminho metodológico homogêneo para todas as atividades realizadas, é possível afirmar que as práticas educativas buscam destoar de uma concepção tradicional de ensino, que considera o estudante como objeto e os conteúdos conceituais como acervo de conhecimentos a serem acumulados. Ou seja, as intervenções realizadas buscam consolidar novas formas de ensinar Ciências, apropriando-se de novos instrumentos e proporcionando diferentes formas de aprender.

\section{Eixo 3 - Tendências teóricas}

Foram identificadas algumas matrizes teóricas que parecem balizar as práticas pedagógicas do subprojeto Ciências da Natureza. Essas matrizes são: formação de professores, referenciais ligados a questões ambientais e letramento científico.

Os referenciais de formação de professores podem ser reconhecidos pelos 
planejamentos, grupos de estudo, reflexões, sistematização e socialização das experiências, havendo estudos referentes à constituição do ser professor como Nóvoa (2007), (NÓVOA, 2007) e os processos de formação, em que utilizam Freire (2016). Identificaram-se também alguns referenciais ligados a questões ambientais e estudos sobre Educação Ambiental (GERVASIO et al., 2018; POPPE; SCHMITZ; VALENTE, 2016), e ainda discussões sobre letramento científico vinculadas às orientações da BNCC (BRASIL, 2017).

Foi possível perceber estudos referentes a essas dimensões de forma distinta, em que ora estudaram-se processos de constituição do ser docente, ora referenciais que abordam as questões ambientais, em uma perspectiva crítica. Além disso, também foi possível identificar certa articulação desses aspectos nos planejamentos e discussões que se apresentam no relatório. Essa articulação é demonstrada na figura a seguir (Figura 1):

Figura 1: Articulação entre os referenciais das práticas pedagógicas do subprojeto Ciências da Natureza.

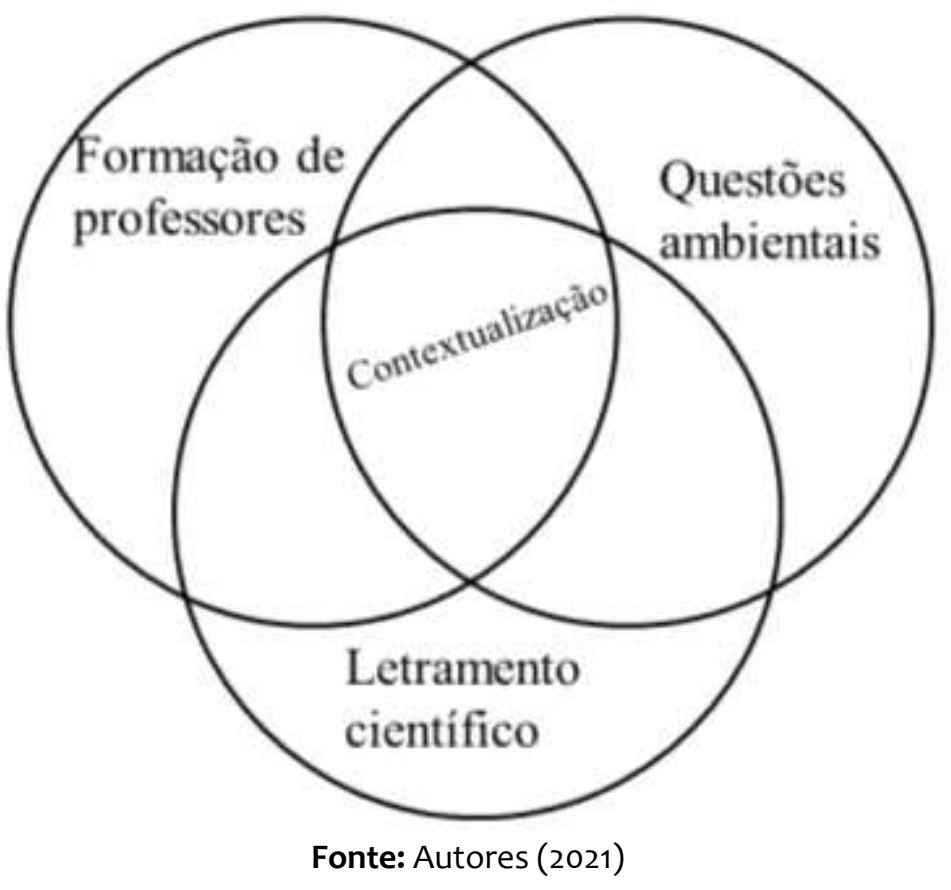

A dimensão da formação de professores é materializada pelo aspecto coletivo de planejamento e diálogo nas práticas educativas. As questões ambientais são postas pela abordagem da realidade e a articulação com os saberes populares. O letramento científico está presente nos objetivos propostos pelos planejamentos, em que visam estimular a capacidade do estudante em interpretar diferentes situações presentes na sociedade, além de emitir opiniões e se posicionar. A intersecção das três dimensões (formação de professores, questões ambientais e letramento científico) é contemplada pela caracterização de uma prática contextualizada, que abrange aspectos presentes na sistematização de processos educativos, visando uma formação cidadã.

É importante mencionar que o letramento científico é conceito ainda em discussão 


\section{-Revista de Iniciação à Docência, v.6, n.2, 2021- \\ Publicação: dezembro, 2021 - ISSN 2525-4332}

na área de Ensino de Ciências. O conceito discutido no Programa é o que consta na BNCC, que é definido como: "[...] a capacidade de compreender e interpretar o mundo (natural, social e tecnológico), mas também de transformá-lo com base nos aportes teóricos e processuais das ciências" (BRASIL, 2017, p. 319).

Krasilchik e Marandino (2004) consideram que o conceito de alfabetização científica já contém os ideais do letramento científico, não sendo necessária essa diferenciação. Mamede e Zimmermann (2005) assumem a alfabetização científica como aprendizagem de conteúdos científicos e o letramento científico como o uso desses conceitos no cotidiano. Já para Chassot (2006), alfabetização científica é um conjunto de conhecimentos que facilitam homens e mulheres fazerem uma leitura do mundo. Assim, o Programa parece trabalhar com os princípios do letramento científico, enquanto apropriação de conhecimento para inserção em um contexto social, ainda que não discutam amplamente essa vertente teórica.

Um referencial que balizou muitos dos planejamentos dos licenciandos foi a BNCC, que foi alvo de discussões que antecederam a articulação das práticas do Programa. Baseado no relatório pode-se notar que um grupo de estudos considera o documento como uma criação coletiva, ou seja, que foi pensada por muitos especialistas, contribuindo para articular uma aprendizagem global ao estudante e considerando características regionais/locais nas práticas educativas, além de mencionarem aspectos contemporâneos, como as relações entre Ciência e Tecnologia e discussões ambientais. No entanto, é importante considerar o contexto de produção desse documento. Segundo Flôr e Trópia (2018), a BNCC foi elaborada em um cenário de instabilidade política, com muitas trocas de atores em cargos de poder na Educação. Tais atores não dialogaram entre si, o que contribuiu para o alinhamento do documento a metas internacionais educacionais de caráter neoliberal em detrimento de considerações à produção científica nacional. Flôr e Trópia (2018) afirmam, ainda, que nas orientações para Ciências da Natureza, há uma ausência de referências a produções de eventos em Educação e em Educação em Ciências, como o ENPEC, por exemplo, que divulgam e disseminam muitos conhecimentos e demandas nessas áreas. Isso revela uma tensão entre o discurso autoritário da lei e o discurso das Ciências da Educação.

Ainda sobre as discussões entre letramento científico e alfabetização científica, se assumida como uma articulação com questões ambientais, como indicado na Figura 1, precisa abordar dimensões sociais, econômicas e culturais. De certa forma, tais dimensões estão presentes nas práticas realizadas, ainda que inseridas por meio de componentes curriculares específicos, por exemplo, ao se tratar questões como custobenefício a Matemática é abordada. Vale ressaltar que há a necessidade de esclarecer que determinados conceitos fazem parte de um componente curricular específico. Práticas educativas comprometidas com uma alfabetização científica podem ocorrer na inserção e discussão de temas, como o bioma Pampa, na perspectiva da Educação CTS ou questões sócio-científicas. Independente do segmento teórico-metodológico é importante, assim 


\section{-Revista de Iniciação à Docência, v.6, n.2, 2021- \\ Publicação: dezembro, 2021 - ISSN 2525-4332}

como mencionado no Eixo 1, sistematizar as práticas a partir de uma problemática.

Em outras palavras, é pertinente que se parta de perguntas, a fim de atender determinada demanda, para não ocorrer um esvaziamento do processo educativo. Essa problemática, segundo Lindemann et al. (2009), não pode resumir-se a um "amontoado" de perguntas que direcionam o ensino, mas sim abordar problemas próximos a situações vivenciadas pelos estudantes.

As práticas realizadas a partir de problemas reais indicam possibilidades de reestruturação curricular via pautas presentes na realidade. Esses processos, quando vivenciados junto com os docentes supervisores da Educação Básica, permitem momentos de co-formação e renovação da prática. Nesse aspecto reside o potencial formativo do PIBID, do mesmo modo que se constitui como uma formação permanente, já postulada por Freire (2016).

Em síntese, pode-se dizer que as matrizes teóricas que balizam as práticas do Programa desenham um marco teórico entre a formação de professores, o letramento científico e os referenciais relacionados a questões ambientais. A efetivação desses estudos materializa-se na articulação de processos que valorizam o contexto, colocandoo como cenário das intervenções e, na maioria das vezes, também é ponto de partida.

\section{Algumas considerações}

O olhar para o relatório de produção do PIBID intencionou verificar quais possíveis temáticas, metodologias e estudos teóricos têm sido desenvolvidos pelo Programa no subprojeto Ciências da Natureza, da Unipampa - campus Dom Pedrito. Assim, não se buscou uma análise detalhada do que foi produzido, mas um panorama amplo do que tem sido abordado. Para isso, realizou-se uma leitura ampliada do relatório, identificando o que tem sido recorrente enquanto aporte teórico-metodológico nas temáticas trabalhadas.

Quanto às tendências temáticas articuladas, percebeu-se uma abordagem vinculada a temáticas ambientais, como o bioma Pampa, e a busca por articulações a experiências e/ou aspectos presentes na realidade dos estudantes. Não se identificou critérios para escolha dos temas, ainda assim são coerentes com uma perspectiva contextualizada de ensino.

No que se refere à dimensão metodológica não é possível assumir uma metodologia que baliza as práticas de forma geral, porém pode-se afirmar que os processos educativos são coerentes com uma concepção progressista de ensino e, nessa perspectiva, perpassam várias maneiras de abordagem, estratégias e recursos.

Já nas tendências teóricas há indicativos de uma prática contextualizada, que se ancora em referenciais que defendem a valorização da figura do professor, no letramento científico e na importância da abordagem de questões ambientais, visando uma formação 
cidadã para os estudantes.

Além das questões do contexto, também há algumas potencialidades pertinentes de serem ressaltadas, como: a abordagem dialogada nas práticas, visto que a análise dos planejamentos indicou que houve a participação dos estudantes por meio de questionamentos; a organização de coletivos de planejamento, que se articula com uma perspectiva interdisciplinar de estudo e implementação das propostas de ensino; a contribuição para constituição da identidade do professor, a partir da sistematização e socialização das experiências pedagógicas na forma de relatos de experiência.

É possível apontar algumas lacunas que podem ser superadas, como a necessidade de assumir as temáticas a partir de uma problemática, para não ocorrer um esvaziamento das práticas; um delineamento metodológico e um aprofundamento em alguns conceitos teóricos, como o letramento científico. Entretanto, esse estudo não teve como foco apontar essas lacunas.

Por fim, é importante mencionar que esse panorama, a partir do relatório de produção do Programa, é uma análise documental que possibilitou perceber potencialidades e lacunas. Porém, reconhece-se também a limitação que essa análise possui, não sendo possível afirmar que algumas articulações estejam totalmente ausentes nas práticas efetivadas, uma vez que o olhar para elas apenas por esse documento é insuficiente. No entanto, ainda que seja uma análise superficial sobre as produções do subprojeto Ciências da Natureza, caracteriza-se como um levantamento pertinente às reflexões tecidas nos próprios grupos de estudo e reuniões de planejamento.

\section{Referências}

AULER, D. Articulação entre pressupostos do educador Paulo Freire e do Movimento CTS: Novos caminhos para Educação em Ciências. Contexto e Educação, v. 22, n. 77, p. 167-188, 2007.

BARDIN, L. Análise de Conteúdo. Lisboa, Portugal; Edições 70, LDA, 2009.

BENCKE, G. Monoculturas podem decretar o fim dos pampas. Entrevista concedida a. Revista do Instituto Humanistas Unisinos, v.1, n. 190.p.10-13, 2006.

BRASIL. Parâmetros Curriculares Nacionais: Ciências Naturais. Secretaria de Educação Fundamental. Brasília: MEC/SEF, 1998.

BRASIL. Base Nacional Comum Curricular. Brasília: MEC, 2017. Disponível em: http://basenacionalcomum.mec.gov.br/a-base. Acesso em: 27 mar. 2020.

BRASIL. Ministério de Educação e Cultura. LDB - Lei nº 9394/96, de 20 de dezembro de 1996. Estabelece as diretrizes e bases da Educação Nacional. Brasília: MEC, 1996.

CAMINHA, J. R. Conhecendo o Bioma Pampa e sua diversidade florística através de uma saída de campo: a Educação Ambiental no Ensino de Ciências da Natureza. 2019. Trabalho de Conclusão (Graduação) - Curso de Licenciatura em Ciências da Natureza, Universidade Federal do Pampa, Dom Pedrito, RS, 2019. Disponível em: 
http://cursos.unipampa.edu.br/cursos/cienciasdanatureza-dp/files/2019/og/reconhecendoo-bioma-pampa.pdf. Acesso em: 03 abr. 2020.

CAPES. Pibid - Programa Institucional de Bolsas de Iniciação à Docência, 2014. Disponível em: http://www.capes.gov.br/educacao-basica/capespibid/pibid. Acesso em: 20 mar. 2020.

CASTRO, L. R. B. O Bioma Pampa como temática de investigação no ensino básico no município de Uruguaiana-RS. Dissertação (Mestrado em Educação em Ciências). Universidade Federal de Santa Maria, Santa Maria, RS, 2018. Disponível em: https://repositorio.ufsm.br/bitstream/handle/1/18612/DIS_PPGEC_2018_CASTRO_LUIS.pdf? sequence=1\&isAllowed=y. Acesso em: 03 abr. 2020.

CASTRO, L. R. B.; CARVALHO, A. V.; PESSANO, E. F. C. Percepções de alunos do ensino fundamental sobre o bioma pampa, no oeste do Rio Grande do Sul, Brasil. Revista Exitus, Santarém/PA, v. 9, n. 4, p. 290 - 318, Out/Dez, 2019.

CENTA, F. G.; MUENCHEN, C. O trabalho coletivo e interdisciplinar em uma reorientação curricular na perspectiva da Abordagem Temática Freireana. Revista Electrónica de Enseñanza de las Ciencias, v.17, n. 1, p. 68-93, 2018.

CHASSOT, A. Alfabetização Científica: questões e desafios para a educação. ljuí: Ed. Unijuí, 2006.

CHASSOT, A. Sete escritos sobre educação e ciência. São Paulo: Cortez, 2008.

CHASSOT, A. Saberes populares fazendo-se saberes escolares: uma alternativa para a alfabetização científica. In: V ANPED SUL: pesquisa em educação e compromisso social, 2004. p.11. Disponível em: http://migre.me/oQ3OS. Acesso em: 03 abr. 2020.

DELIZOICOV, D.; ANGOTTI, J. A.; PERNAMBUCO, M. M. Ensino de Ciências: Fundamentos e Métodos. São Paulo: Cortez, 2011.

FLOR, C. C. C.; TROPIA, G. Um olhar para o discurso da Base Nacional Comum Curricular em funcionamento na área de ciências da natureza. Horizontes, v. 36, n. 1, p. 144-157, jan./abr. 2018.

FONSECA, E. M. da; BIERHALZ, C. D. K. Programa institucional de bolsas de iniciação a docência: análise das publicações do Enpec. Debates em Educação, [S. I.], v. 10, n. 20, p. 199, 2018.

FONSECA, E. M. Abordagem de temas no Ensino de Ciências: Reflexões para processos formativos de professores. Dissertação. (Mestrado em Ensino). Universidade Federal do Pampa, Bagé, RS, 2019. Disponível em: https://dspace.unipampa.edu.br//handle/riu/4593. Acesso em: 13 dez. 2021.

FREIRE, P. Pedagogia do Oprimido. 60ª ed. Rio de Janeiro: Paz e Terra, 2016.

GERVASIO, C. et al. Estudo científico de espécies nativas do bioma pampa como ferramenta para a educação ambiental crítica. In: XVIII SEMINÁRIO INTERNACIONAL DE EDUCAÇÃO NO MERCOSUL, 2018, Cruz Alta. Atas... Cruz Alta, 2018. Disponível em: https://home.unicruz.edu.br/event/mercosul/. Acesso em: 02 abr. 2020.

KRASILCHIK, M.; MARANDINO, M. Ensino de ciências e cidadania. $1^{\mathrm{a} e d}$. São Paulo: Moderna, 2004. 
LINDEMANN, R. H.; MUENCHEN, C.; GONÇALVES, F. P.; GEHLEN, S. T. Biocombustíveis e o ensino de Ciências: compreensões de professores que fazem pesquisa na escola. Revista Electrónica de Enseñanza de las Ciencias, Vigo, v. 8, n. 1, p. 342-358, 2009.

MAMEDE, M; ZIMMERMANN, E. Letramento científico e cts na formação de professores para o ensino de ciências. Enseñanza de las ciencias, n. extra, 2005.

MILLI, J. C. L.; ALMEIDA; E. dos S.; GEHLEN, S. T. A Rede Temática e o Ciclo Temático na Busca pela Cultura de Participação na Educação CTS. ALEXANDRIA: Revista de Educação em Ciência e Tecnologia. Florianópolis, SC, v. 11, n. 1, p. 71-100, mai. 2018.

NOGUEIRA, K. S. C.; FERNANDEZ, C. O impacto do Pibid na formação de professoras experientes. In: ENCONTRO NACIONAL DE PESQUISA EM EDUCAÇÃO EM CIÊNCIAS (ENPEC), 12., 2019, Natal. Atas... Natal: ABRAPEC, 2019. Disponível em: http://abrapecnet.org.br/enpec/xii-enpec/anais/resumos/1/R0233-1.pdf. Acesso em: 02 abr. 2020.

NÓVOA, A. Desafios do trabalho do professor no mundo contemporâneo. Sindicato dos professores de São Paulo: São Paulo, 2007.

POPPE, J. L.; SCHMITZ, H. J.; VALENTE, V. L. S. Diversidade biológica do bioma pampa na região das missões: preservação do patrimônio natural gaúcho. In: II ENCONTRO MISSIONEIRO DE ESTUDOS INTERDISCIPLINARES EM CULTURA, 2016, São Luiz Gonzaga. Atas... São Luiz Gonzaga, 2016. Disponível em: http://docplayer.com.br/25992302Diversidade-biologica-do-bioma-pampa-na-regiao-das-missoes-preservacao-dopatrimonio-natural-gaucho.html. Acesso em: 02 abr. 2020.

SANTOS, T. L.; SANTOS, V. A.; FERREIRA, D. T. Primeiros passos rumo à docência: expectativas de licenciandos do Pibid. In: ENCONTRO NACIONAL DE PESQUISA EM EDUCAÇÃO EM CIÊNCIAS (ENPEC), 12., 2019, Natal. Atas... Natal: ABRAPEC, 2019. Disponível em: http://abrapecnet.org.br/enpec/xii-enpec/anais/resumos/1/R1942-1.pdf. Acesso em: 03 abr. 2020.

SILVA, L.A.R.; MILARÉ, T. Os significados e a natureza dos saberes populares: reflexões e possibilidades no ensino de ciências. Ensaios Pedagógicos (Sorocaba), v. 2, n. 3, p.95-104, set-dez., 2018.

SILVEIRA, T. A.; OLIVEIRA, M. M.; NOGUEIRA, R. A. A formação docente personalista em um pibid interdisciplinar. In: ENCONTRO NACIONAL DE PESQUISA EM EDUCAÇÃO EM CIÊNCIAS (ENPEC), 12., 2019, Natal. Atas... Natal: ABRAPEC, 2019. Disponível em: http://abrapecnet.org.br/enpec/xii-enpec/anais/resumos/1/R1370-1.pdf. Acesso em: 03 abr. 2020. 